\title{
Research on Human Resource Integration in Transnational Mergers and Acquisitions for Chinese Enterprises
}

\author{
Wenxing Sun ${ }^{1, a, *}$, Pu Li ${ }^{1, b}$ and Chengcheng $L i^{1, c}$ \\ ${ }^{1}$ School of Management Science and Engineering, Shandong Normal University, Ji’nan, 250014, China \\ a373253360@qq.com, b1141187104@qq.com, c 1402045013@qq.com \\ *corresponding author
}

Keywords: Transnational Merger and Acquisition; Human resource integration; countermeasure

\begin{abstract}
With the rapid development of economic globalization, transnational mergers and acquisitions (m\&a) have become one of the main ways for enterprises to reach the international market, expand the scale of enterprises and seek competitive advantages. But whether cross-border m\&a can achieve the desired effect is the key to the management integration after the merger, and the integration of human resources is crucial. This paper combed the development course of Chinese enterprises transnational $\mathrm{m} \& \mathrm{a}$, analyses the risks existing in Chinese enterprises transnational mergers and acquisitions, as well as the status quo of human resources integration, to study the Chinese enterprises transnational mergers and acquisitions in the problems faced by the human resources integration, puts forward the corresponding countermeasures.
\end{abstract}

\section{Introduction}

Since the 1990s, the international business environment has undergone major changes, and the trend of economic globalization and integration has been developing rapidly. In order to adapt to changes in the environment, maintain international competitive advantages, and strengthen its strategic position in the international market, companies across the world have launched a huge wave of fifth mergers and acquisitions around the world.[1] After China's entry into WTO, the domestic market will be opened step by step according to the relevant agreements and commitments, and multinational companies will enter the Chinese market more vigorously in the form of crossborder mergers and acquisitions.[2] At the same time, Chinese companies' cross-border mergers and acquisitions also show a momentum of growth and become a new way for overseas development. In 2004, Lenovo completed the feat of annexation of the IBM personal computer business, which pushed the frenzy to the top. Compared with the newly established investment, mergers and acquisitions can enable companies to enter the international market faster and easier, and quickly use the original advantages of the enterprise, can save construction time, directly use existing equipment, production management personnel and sales network, and be more adaptable to changes in economic globalization, integration, and international business environment.[3]

However, the completion of transactions of mergers and acquisitions does not represent the success of mergers and acquisitions. According to the CFO magazine's survey of 45 merger and acquisition enterprises in the top 500 companies of the world, $75 \%$ of mergers and acquisitions are disappointing or completely fail, and the main reason is the failure of integration of "Human". The relevant data shows that the success rate of overseas mergers and acquisitions by Chinese companies is less than $30 \%$. Human resources as the core competitiveness of enterprises, the effectiveness of its integration is directly related to the success or failure of mergers and acquisitions. Therefore, research on the integration of human resources in cross-border mergers and acquisitions of enterprises is of great significance to the operation and development of Chinese companies' cross-border mergers and acquisitions. 


\section{Analysis of the Problem Existing in the Integration of Human Resources in Chinese Enterprises' Transnational Mergers and Acquisitions}

\subsection{Destruction of the stability of the organization}

Mergers and acquisitions inevitably destroy the stability of the organization and cause some confusion in the organization.[4] In order to fully exploit the value of mergers and acquisitions and bring into full play the integration effect, the organizational structure and human resources of enterprises will undergo large-scale adjustment and reorganization for many industrial mergers and acquisition. In most mergers and acquisitions, the operating performance of target enterprise will continue to decline in the first few months after the merger, and usually takes 6-12 months to gradually get out of the trough. The organizational disruption caused by the M\&A process itself is not necessarily a bad thing.

\subsection{Cultural Conflicts in Transnational Mergers and Acquisitions}

The challenges faced by Chinese enterprises in transnational mergers and acquisitions from the cultural differences between the East and the west can be analyzed from the following two aspects.[5]

1) National cultural differences between the two sides of the M\&A. The cultural differences between M\&A parties are enormous, because they face not only organizational culture differences and conflicts from the corporate level, but also national cultural differences and conflicts, which are mainly reflected in the degree of power, individualism and collectivism, Masculism and feminism, long-term orientation and short-term orientation.

2) The differences in the degree of cultural identity between the two sides of the M\&A. Facing the double differences between national culture and corporate culture in transnational mergers and acquisitions, the recognition and acceptance of each other's culture by both sides of the merger and acquisition become the key factor of cultural integration. In the process of overseas expansion of Chinese companies, the employees, media, investors, and even labor unions of the countries in which the merged companies are located still have a skeptical attitude toward Chinese companies.

\subsection{The loss of core human resources}

The core human resources refer to the employees who master the company's core technology, marketing, management and other knowledge and skills, and create the most performance of companies on which the company's development depends. The core competitiveness of a company is highlighted by its core human resources.

After mergers and acquisitions, there is often a higher turnover rate. Because mergers and acquisitions bring great impact and uncertainty to companies and employees, if they do not take active measures to retain the employees of the merged company, they will leave the company several years before the merger, especially senior management and technical personnel.[6] Since the core human resources hold many important information and technologies such as the production, operation, and manufacturing of enterprises, once they are lost to the company, not only the loss of talent, but also the threat to the company's trade secrets.

\subsection{Incentive of the retained staff and Redundant placement}

In the integration of human resources, leaving the core staff is only the first step in integration. In the actual process of merger and acquisition, the psychological impact of $\mathrm{M} \& \mathrm{~A}$ on employees is lagging. Even if employees do not leave the business because of this impact, the influence of this impact on their psychology cannot be ignored. It will inhibit the exertion of the working motivation of the remaining staff and thus affect the performance of the whole organization. Therefore, how to give full play to the enthusiasm of the retained staff and how to motivate them effectively is another big problem facing the integration. In mergers and acquisitions, enterprises need to lay off some staff due to the adjustment of new company's business strategy or the need to merge business, streamline institutions and improve management efficiency. If the resettlement problem is not 
properly addressed, it will have a negative effect on the incentives of the remaining personnel, and even result in the large-scale loss of people who should not occur.[7]

\subsection{Psychological impact and negative impact of employees}

M \& A is the break and reorganization of various resources such as existing management system, enterprise culture and organizational structure, which will undoubtedly make employees feel uncertain about the future.[8] When they learned of the news that the company was merged, their emotional attitudes would be significantly affected, causing them to feel insecure and their employees' sense of responsibility and loyalty to be diluted.

\subsection{Impact on employee behaviour}

When employees feel insecure, they will take self-protection actions. Many employees' behavior that is not conducive to merger integration and business operation will appear in the enterprise, such as the obstruction of communication and the decline of efficiency. So the cohesive force of the company is destroyed. The work that needs cooperation and team work is in a predicament, which will cause double losses to human capital and business performance.

\section{Countermeasures for the Integration of Human Resources in Transnational Mergers and Acquisitions of Chinese Enterprises}

\subsection{The adjustment and reengineering of the organization structure}

Whether or not the organizational structure is reasonable and clear determines the operational efficiency of the organization. Therefore, the restructuring and reconstruction of organizational structure is an important task for human resources management after M\&A. In accordance with the strategic requirements of mergers and acquisitions, combined with the actual situation of the original organizational structure, enterprises should adjust or reconstruct an institutional framework and institutional norms that can effectively organize and coordinate the company's human, financial, material, supply, production, and sales.[9] In the process of implementing the reengineering of the organization structure, we can start from the following aspects:

According to the company's development strategy, management level and the characteristics of mergers and acquisitions, design appropriate levels of management, and effectively divide departments at all levels to decompose and determine work tasks. There are mainly two modes of management level selection: one is a flat organizational structure and the other is a hierarchical organizational structure. If the company's products are relatively monotonous and the market is relatively stable, the goal of M\&A is to reduce production costs and increase labor productivity and price competitiveness by achieving economies of scale, the enterprises are more suitable for the hierarchical organizational structure which makes the division of labor of the organization more detailed and specialized, and the management personnel can easily implement effective control over the organization after the M\&A.

\subsection{Effective cross cultural integration}

Transnational mergers and acquisitions not only involve different corporate cultures, but also involve different ethnic cultures. This has virtually increased the complexity of cultural integration in transnational M\&A. Therefore, effective cultural integration is not simply to use one culture to transform another culture or impose it on the other, but to find a compatible entry point between the two cultures.[11] Through the point of entry, the integration of the two cultures are constantly strengthened in integration between the core values and target vision level and compatibility on the non-core level. Through the following steps, intercultural integration can be better carried out.

\subsubsection{Understand potential cultural differences and conflicts before $M \& A$}

Transnational cultural integration should begin before M\&A. Before the M\&A, it is necessary to collect selected target corporate culture information.[10] Not only to collect tangible "objects" and behavioral information that the enterprises of various signs, working environment, regulations and 
formal terms used in documents, planning procedures, conference papers and etiquette that people meet, daily behaviors of employees, but also to explore hidden cultures which hidden behind such as organizational philosophy, values, organizational ethos, unwritten rules of behavior on this basis. For transnational mergers and acquisitions, the collection of cultural information must pay attention to collecting the dominant culture of the country where the target company is located.

\subsubsection{Develop an effective cultural integration plan}

After a detailed analysis of the culture of the target company and the host country, we should start to study how to combine two different corporate cultures so as to successfully overcome the cultural and non-cultural conflicts between the two parties. It is necessary to formulate an effective cultural integration plan, establish a team responsible for integration, introduce the company's culture and rules to new managers, and involve top management personnel. The company's senior management team and the integration team should work together with the new manager to develop an integration plan and communication plan, including a timetable and specific operation plans, and establish a work project so that the employees of the two companies can work together and achieve new goals together.

\subsubsection{Treat each other's managers carefully}

Since mergers and acquisitions are a major change for the acquiree, most people will have a sense of crisis and anxiety. Before and after mergers and acquisitions, companies will have greater shocks and turmoil. In order to achieve cultural unification, the support of senior managers, especially the original companies, is indispensable.

\subsubsection{Actively absorb the advanced culture of foreign companies}

At present, most of the Chinese companies' multinational mergers and acquisitions are mature enterprises in the West. From the above analysis of cultural conflicts, we can see that they currently have low recognition of Chinese corporate culture, and that they have a high degree of recognition of their corporate culture and want to maintain their own culture. Therefore, when Chinese companies engage in transnational mergers and acquisitions, they must pay attention to absorbing advanced factors in foreign corporate culture.

\subsection{Retention of core human resources}

In the integration process, we must first determine the core talents that the company will depend on in the future. Then appoint a high-level person responsible for stabilizing these key talents, determine the suitable position of these personnel, the means to retain them, their personal development needs and the satisfaction level of incentive requirements, and timely feedback this information to senior management. To ensure that most of the core employees can remain in the new business, it is important to have substantial incentives.

\subsection{Establish an effective incentive mechanism}

Employees with different cultural backgrounds have different needs. When undertaking crossborder mergers and acquisitions, companies must fully understand the real needs of M\&A employees and discover their value, and reconstruct the incentive mechanism to meet the needs of M\&A employees in different cultures. In the design of incentive mechanisms after mergers and acquisitions, the appropriate combination of material incentives and spiritual incentives should be adopted. On the one hand, in corporate mergers and acquisitions, the first consideration of employees is whether they can guarantee and enhance their own economic benefits after mergers and acquisitions. Therefore, certain material incentives are indispensable. In general, we must ensure that employees have vested interests and use more favorable material interests to attract and stabilize core talents.

\subsection{Strengthen effective communication}

After the completion of the M\&A transaction, human resource integration should quickly 
address the psychological impact of M\&A on employees, communicate with employees in a timely manner, and relieve staff pressure. In the effective communication process, the following methods can be adopted: The first is to clarify the corporate goals after the merger and acquisition. A truly integrated, widely influential vision can revive people's energy and rejuvenate their vitality; The second is to introduce personnel relocation plans as soon as possible during the merger and acquisition process, clarify the division of posts, and reduce employees' suspicions about the job prospects; The third is to understand the needs of employees, clearly communicate goals, formulate communication plans, accurately transmit information, and eliminate the prejudice of foreign enterprise employees against Chinese companies.

\section{Conclusions}

As a flow mode of capital internationalization, transnational mergers and acquisitions (M \& A) promote the rapid development of China's economy as well as new impetus to the world economy. After China's entry into the WTO, the integration of the domestic market with the international market has prompted Chinese entrepreneurs to think more deeply about the future direction of development. Therefore, the study of transnational mergers and acquisitions has an important role in the survival and development of Chinese enterprises. However, mergers and acquisitions are not the aim, and how to achieve the expected synergy of mergers and acquisitions is a common problem facing Chinese and foreign enterprises. All of the spearheads point to merger integration, especially the integration of human resources. The transnational merger and acquisition in China started relatively late, and it is not mature in theory and practice. There are many problems in the integration of human resources, such as the stability of the organization, cultural conflicts, the loss of core human resources, the incentives of retained personnel and the placement of redundant personnel, the psychological impact on employees, and the impact of behavior.

\section{References}

[1]Wang Z M, Yang B. Economic influence and Chinese countermeasure, analytical thinking of the newest wave of corporation merger \& acquisition[J]. Journal of Suzhou University, 2000.

[2] Cheng $\mathrm{H}$. Research on the Influence and Countermeasure of the Enterprises in China Facing the Merger and Acquisition[J]. Journal of Hubei Water Resources Technical College, 2007.

[3] Chen A X, Branch J T. Conflict and Countermeasure of Human Resource Integration after Merger and Acquisition of Enterprises Changed from Institutions: Taking $\mathrm{T}$ Branch as an Example[J]. Value Engineering, 2017.

[4] Li C. Analysis of Issues and Countermeasure of Chinese Enterprise Overseas Merger and Acquisition[J]. Reformation \& Strategy, 2011.

[5] Ran Z R. The Integration Risk of Chinese Enterprises' Cross Border Merger and Acquisition and Countermeasures[J]. Journal of International Trade, 2006.

[6] Wang W, Xifeng L I. Operational Bottlenecks and Countermeasure Analysis with Regard to Post-Merger Overseas Resources of China's Enterprises[J]. Natural Resource Economics of China, 2013.

[7] Feng P C, Sun Y, Zhang Y C. Problems and Countermeasures of Human Resources Integration in Transnational Mergers and Acquisitions[J]. Science \& Technology and Economy, 2010, 23(4):69-72.

[8] LI C Y. Research on the Integration of Human Resources in Chinese Enterprises' Transnational Mergers and Acquisitions[J]. Reformation \& Strategy, 2014(6):111-114.

[9] Zhou J B, Song X. Research on Human Resource Integration Strategies in Corporate Transnational Mergers and Acquisitions[J]. Journal of Shijiazhuang University of Economics, 2015, 38(2):90-93.

[10] Zhang L J, Wu S Y, Gao J. Research on the Countermeasures of Human Resources Integration of Chinese Enterprises' Transnational Mergers and Acquisitions[J]. China Business Update, 2010(12):74-74. 
[11] Li J. Research on Human Resources Integration in Transnational Mergers and Acquisitions of Enterprises[J]. Journal of Tianjin Vocational Institutes, 2016, 18(3):59-63. 